\title{
EDITORIAL
}

\section{Preface of special issue of the $10^{\text {th }}$ International Conference on $\mathrm{CO}_{2}$ Utilization}

\author{
Changjun LIU * $(\bowtie)$ \\ Key Laboratory for Green Chemical Technology, School of Chemical Engineering and Technology, Tianjin University, Tianjin 300072, China
}

(C) Higher Education Press and Springer-Verlag Berlin Heidelberg 2010

This special issue contains peer-reviewed manuscripts presented at the 10th International Conference on $\mathrm{CO}_{2}$ Utilization (ICCDU-X), Tianijn, China, May 17-21, 2009. The guest editor is grateful to Tianjin University, National Natural Science Foundation of China, Tianjin Key Laboratory of Catalysis Science \& Technology, Agilent, Quantachrome, Frontier of Chemical Engineering in China and Energy \& Environmental Science for their sponsorship.

Carbon dioxide is the largest man-made greenhouse gas. The emission of carbon dioxide has led to a more and more serious global warming. How to deal with carbon dioxide is a significant challenge to governments, industries and societies worldwide. On the other hand, it has been well known that carbon dioxide is the largest carbon resource for various syntheses. The utilization or chemical fixation of carbon dioxide would be a final solution to the global carbon dioxide problem. This special issue focuses on the utilization of carbon dioxide with other related important aspects, like capture, separation and low-carbon emission options. Especially, several authors presented their new ideas for the first time in papers in this special issue. The guest editor believes that the papers presented here will be helpful for the future development of this truly international field.

The guest editor thanks all the authors for their excellent contributions and also for their understanding and collaborations. The guest editor also acknowledges all the referees for their reviews that make this quality issue possible.

E-mail: ughg_cjl@yahoo.com

*Prof. Changjun LIU is the Changjiang Distinguished Professor of Chemical Technology, the Chair of the 10th International Conference on $\mathrm{CO}_{2} \mathrm{Utilization}$ and the 2010 Program Chair of the Fuel Chemistry Division of American Chemical Society 